\title{
Urinary Bladder Stone Removal Surgery in Sulcata tortoise (Geochelon sulcata) with Lateral Plastron Osteotomy Technique
}

\author{
Dian Ayu Kartika Sari* and Desty Apritya \\ Faculty of Veterinary Medicine, University of Wijaya Kusuma Surabaya,East Java, Indonesia \\ *Corresponding author's Email: dianayukartika@uwks.ac.id; (DORCiD: 0000-0002-8595-3956
}

\begin{abstract}
This paper aimed to examine the management of urinary calculi of a sulcata tortoise. A 5-year-old Sulcata tortoise (Geochelon sulcata) was presented with a history of dehydration, loss of appetite, and lameness. Clinical signs and radiographic examination indicated urinary calculi in the urinary bladder. Radiographic results revealed that there was a radiopaque urinary calculi mass. Plastron osteotomy and cystotomy techniques were used to remove urinary calculi. The appetite of the tortoise returned to normal in a week after the surgery. The lateral plastron is an appropriate osteotomy technique, especially for the immediate opening of the plastron with a stone-filled bladder. This was a safe area to open plastron since it was far from the heart. This method was not beneficial for the tortoise in their infancy since it would interrupt the development of plastron formation resulting in the postoperative asymmetrical plastron structure.
\end{abstract}

Keywords: Urinary calculi, Cystotomy, Plastron osteotomy, Sulcata tortoise

\section{INTRODUCTION}

Urinary calculi are solid calculi primarily found in the urinary bladder while regularly calcified, it forms non-calcific material. Tortoise urinary calculi are mainly composed of urates, a mixture of uric corrosive and metals, such as sodium, potassium, or calcium (Wright, 2008). Uroliths have been reported in amphibians, lizards, turtles, and snakes. These are mainly due to the accumulation of uric corrosive and no entry into water supplies leading to tortoise dehydration (Girolamo and Mans, 2016).

Cystotomy is a surgical incision into the bladder for the expulsion of urinary calculi, which is of utmost importance for a tortoise and might be huge. Depending on the organisms, surgical approaches to the coelom differ widely. Two methodologies of turtle coelom surgeries are plastron osteotomy and coeliotomy of the femoral fossa (Mitchell and Tully, 2008). The most suitable choice depends on the species and the exciting organ. Appropriate preparation of the reptile patient for coeliotomy is mandatory. Coeliotomy using the transplastron coeliotomy or plastron osteotomy approach allows the manipulation of the bladder through which the plastron is opened to approach the bladder in the caudoventral aspect of the coelomic cavity (Mitchell and Tully, 2008). Some of the techniques that have been used by (Girolamo and Mans, 2016) are plastron perforations in the central part. In some cases, it is important to consider the exposed plastron due to the surrounding veins and the heart $b$. When the plastron opens in the horizontal zone it reveals vesica filled with stones. Most of the innovative surgical techniques, as in another medial area, are described in papers, case series, or other empirical studies. This paper discusses the advantages and disadvantages of lateral plastron osteotomy techniques.

\section{MATERIALS AND METHODS}

A sulcata tortoise (Geochelon sulcata) was referred to the Out-Patient Clinics of DRD Veterinary in Surabaya, Indonesia, with a history of dehydration, loss of appetite, and lameness. Based on the clinical symptoms, an X-ray examination was performed (Figure 1) and a dorsoventral radiograph was taken. The results revealed an enhanced radioopacity at the middle-left of the coelomic cavity indicating urinary calculi. The administered general anesthetic drugs included a combination of tiletamine and zolazepam with a dose of $10 \mathrm{mg} / \mathrm{kg}$ body weight (Zoletil ${ }^{\circledR}$ from France). The size of the incision usually depends on the urinary calculi size observed in the radiography interpretation.

For a plastron osteotomy, the tortoise was positioned in dorsal recumbency (Figure 2A). The opening of the plastron was performed through the lateral abdominal shields using a circular mini grinding saw for home use. The entry 
point was rectangular with a $45^{\circ}$ tendency. It was inundated with saline during the plastron osteotomy (Alworth et al., 2011). Firstly, the two lateral cuts were made, and a pincet was used to ensure the maximum thickness of the cuts, and the shell was pierced over the core. Using a forceps clamp, the cranial edge of the plastron was raised to reveal the muscle. To separate the plastron osteotomy segment from the underlying soft tissue, blunt dissection was used (Divers, 2012). The paired abdominal veins were closely connected with the plastron, and careful removal of the flap periosteum was required to maintain these vessels with the rest of the soft tissues (Figure 2B). The caudal soft tissue connections could be left unblemished as the plastron fold was reflected caudally and secured with ordinary saline. Stay suture was regularly utilized to forestall coelomic tainting by nonsterile urine, and liquid substance was suctioned before the entry (Figure 3).

The dorsal perspective was incised on the urinary bladder with sharp blade number 10. In the next step, urinary calculi were removed from the body of the tortoise. The bladder was flushed by sterile saline and closed with a clear continuous pattern using the absorbable suture. The coelomic membrane was closed in a continuous pattern using Safil ${ }^{\circledR}$, Braun Surgical, Spain (Stephen and Scott, 2019). The recovery technique for the plastron legitimately relied on the quality of the repair. Precise reduction of the hard segment and plastron can increase the likelihood of recovery from the first or second target. Nonetheless, the plastron fold becomes a sequestrum that gives the fresh bone producing underneath a brief assurance (Girolamo and Mans, 2016).

The shell was thoroughly washed with an alcohol swab to remove any grease before using epoxy resin to seal the region where antibiotic powder and powder gips were added. In this regard, it was highly important to prevent infection and accelerate the healing process (Rodrigues et al., 2015). During 12-18 weeks, the recovery of plastron was observed. The coating material (i.e. epoxy resin) remained in place for 6-12 months before removal. The recuperate of the plastron bone fold could differ during the first two years.

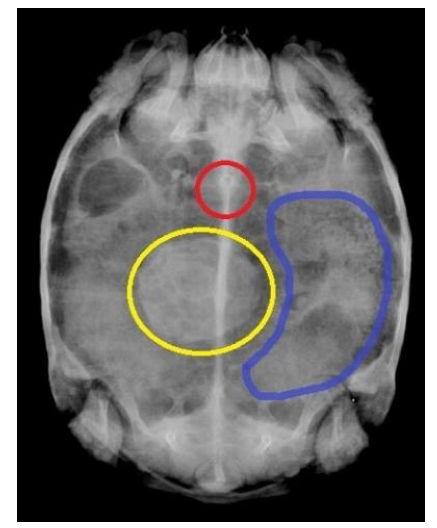

Figure 1. Dorsoventral radiographic image. Radiography interpretation of urinary calculi in vesica urinaria. An extensive mineral, opaque, rounded structure is seen in the mid-left lateral coelom (Yellow: urinary calculi, blue: large intestine, red: hearth).
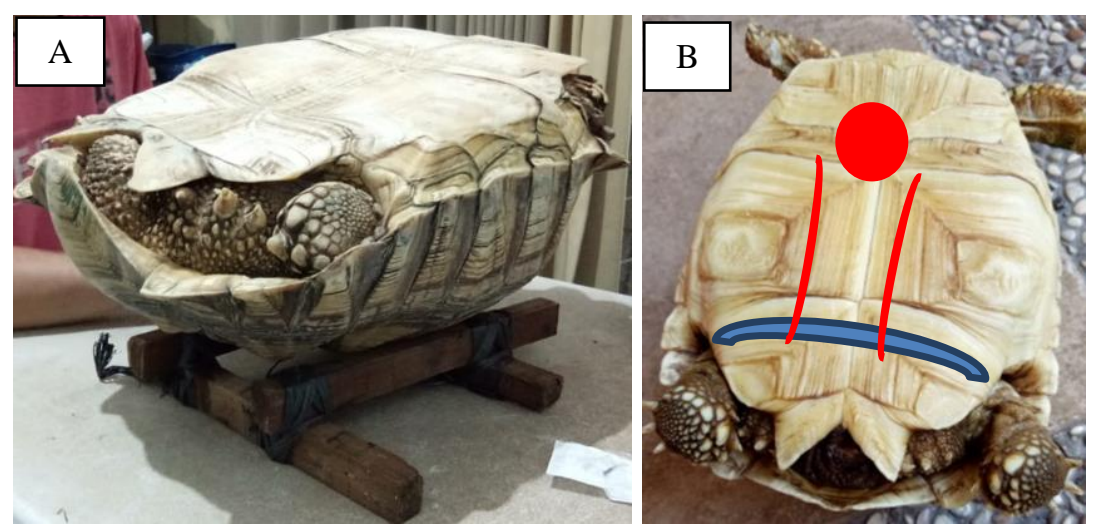

Figure 2. Tortoise is positioned in dorsal recumbency. A: Preparation before surgery. B: View of the centrum of a tortoise illustrating the position of the heart (red circle), paired ventral abdominal veins (red lines), caudal plastron hinge (blue line).
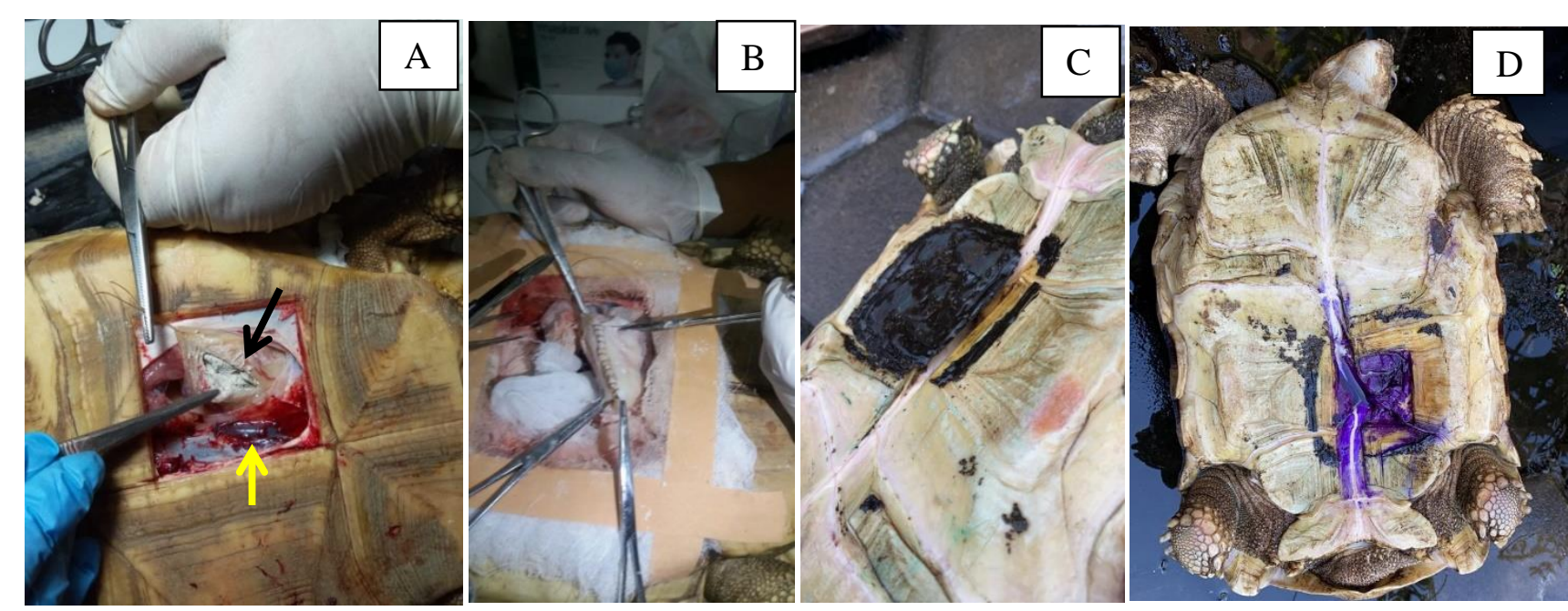

Figure 3. Plastron osteotomy in tortoises. A: The yellow arrow shows the abdominal vein, and the black arrow shows urinary calculi still inside of vesica urinaria. B: Closed vesica urinaria with simple continues the pattern. C: Final repair, repositioned, and held in place by epoxy plastron flap. D: An asymmetric plastron was observed six months after surgery. 


\section{Ethical approval}

This article is not an experimental investigation. This experiment was performed according to all ethics and animal welfare in DRD Veterinary Animals Clinic in Surabaya, Indonesia.

\section{RESULTS AND DISCUSSION}

A tortoise is a type of animal that may experience urinary calculi. In the form of uric acid, reptiles excrete their nitrogenous waste. Uric acid is water-insoluble and thus water cannot be used to dissolve it. The process of dissolving uric acid occurs to prevent the loss of water in reptiles, in particular desert tortoise. This mechanism is the key factor in the formation of calculi in reptiles. Calculi formation starts with the degradation of the protein into a nucleic acid. The nucleic acid in the diet is then degraded to nucleotides by nucleases. These nucleotides undergo additional enzymatic hydrolysis for the processing of free purines and pyrimidine bases. The amino acid is synthesized in the liver with additional purines and pyrimidine bases. If the body does not reuse these free bases, they are further depleted and eventually removed. The pyrimidines are catabolized to give the final products (CO2 and NH3). Purines in reptiles may undergo further breakdowns. Purine is degraded into guanine and adenine. Adenine is converted to hypoxanthine and converted by xanthine oxidase into xanthine and ultimately converted by xanthine oxidase into uric acid. Guanine is immediately transformed into xanthine and then converted into uric acid. In the bladder, uric acid is stored and combined with other cations, such as potassium, resulting in urate precipitation. In the end, the prolonged accumulation of urate salt contributes to calculi formation (Amat et al., 2012).

Calculi plans may be forestalled. The arrangement of calculi is significantly influenced by the tortoise's hydration status. Access to a clean and shallow container of water should be given to the tortoise (Amat et al., 2012) by supplying the tortoise with fresh water sources, such as ponds, or spraying water on their body. For drinking, urination, and even defecation, tortoises require water. In case of dehydration, the tortoise automatically holds their urine helping them to prevent further loss of water. Long accumulation of urine can ultimately contribute to the formation of calculi. Moreover, the tortoise diet should not include a high level of protein.

High protein diets contribute to further protein breakdown and formation of uric acid, which is the key component for the formation of calculi (Miller and Eric, 2015). The tortoise should be fed with vegetables and grass to have a balanced diet and enough nutrients. The diet should be rich in fiber and minerals, such as calcium, vitamin A, and vitamin D, in particular the calcium-phosphorus ratio, which is one of the components that contributes to the development of calculi with an average calcium-phosphorus ratio of 2:1 (McArthur et al., 2004).

To establish a correct diagnosis, it is important to have the history and $\mathrm{x}$-ray examination of the tortoise. Radiography is necessary to confirm the diagnosis, especially in tortoise (Azlan et al., 2015). The dorsoventral view was taken on the radiograph. The radiograph is adequately clear in this case to diagnose that the urinary calculi were radiopaque. There are some methods to extract the urinary calculi, including cystotomy, but in tortoise, opening the plastron is necessary, which is plastron osteotomy (Mitchell and Tully, 2008). The most popular procedure is plastron osteotomy as it provides access to the bladder. Prolonged recovery and rehabilitation are frequently associated with this invasive procedure. The non-invasive technique is designed to extract urinary calculus under sedation or anesthesia through the vent with forceps. The drawback of this approach involves instances where the calculus is stuck within the pelvic region or where forceps will imagine the calculus and palpate it directly from the vent (Amat et al., 2012).

In the present case, the lateral plastron osteotomy technique is used. These strategies approached with negligible obtrusiveness as well as easy and straight forward endurance rates into the coelomic cavity. In the current study, plastron osteotomy was conducted, however, the surgeon's preference was to have more full access to the coelomic cavity (Keller and Weber, 2015). In comparison with medial plastron osteotomy technique, the solution to the lateral plastron osteotomy procedure can be even safer for the urinary bladder to conduct since there is less contact with the vein and the heart is not exposed. It is not advised to ligate both abdominal veins due to the possibility of serious circulatory disturbance (Stephen and Schot, 2019).

After six months of post-operation, the plastron structure was asymmetric due to the growth phase of tortoise plastron. The new growth of the plastron was not balanced between the right and left side since the incision was made in the lateral region. Although the shape of the plastron was not asymmetrical, behavior and appetite seemed to be good.

\section{CONCLUSION}

The proper surgical treatment for tortoise urinary calculi is a cystotomy performed using a lateral plastron osteotomy technique. This technique can only be conducted over the urinary calculi region so that the urinary bladder is much simpler to perform. There was a negligible contact of the vein in the present study and the heart was not exposed. This technique can cause asymmetrical plastron structure in the future. In a tortoise that reached to the limitation of growth, this technique can be used. 


\section{DECLARATIONS}

\section{Authors' contribution}

DAK.Sari is owner of DRD Veterinary Clinic. DAK.Sari and D.Apritya wrote the manuscript. D.Apritya checked and edited the final draft of the article. Both authors confirmed the final form of the manuscript for publication in the journal.

\section{Competing interests}

The authors have not declared any conflict of interest.

\section{Acknowledgments}

This research was funded by DRD Veterinary Clinic, Indonesia. The authors would like to acknowledge their gratitutde to Yayasan Wijaya Kusuma and Wijaya Kusuma Surabaya University.

\section{REFERENCES}

Alworth LC, Hernandez SM, and Divers SJ (2011). Laboratory Reptile Surgery: Principles and Techniques. Journal of the American Association for Laboratory Animal Science, 50(1): 1-16. Available at: https://www.ncbi.nlm.nih.gov/pmc/articles/PMC3035398/

Amat AC, Gabriel B, and Chee NW (2012). Cystic calculi removal in African spurred Tortoise (Geochelone sulcata) using transplastron coeliotomy. Veterinary World, 5(8): 489-492. DOI : https://doi.org/10.5455/vetworld.2012.489-492

Azlan CA, Saw MH, Noorshimah R, Cheah EHC, Lam JL, and Jefri NM (2015). Plastron Osteotomy in The Management Of Fishing Hook Ingestion In a Malayan Box Turtle (Cuora ambonensis). Malaysia Veterinary Journal, 27(1): 12-15. Available at: https://storage.unitedwebnetwork.com/files/478/f53a87f4bfa28724caf0a6b0af6efbb1.pdf

Divers SJ (2012). An Introduction to Reptile Surgery: A Chance to Cut is a Change to Cure. Proceedings:NAVC Conference Small Animal. Available at : https://www.vetfolio.com/learn/article/an-introduction-to-reptile-surgery-a-chance-to-cut-is-a-chance-to$\underline{\text { cur }}$

Girolamo ND, and Mans C (2016). Reptile Soft Tissue Surgery. Veterinary Clinics of North America Exotic Animal Practice Journal, 19: 97-131. DOI: http://dx.doi.org/10.1016/j.cvex.2015.08.010

Keller KA, and Weber EPS (2015). Diagnosis and Treatment of urolithiasis in client-owned Chelonians:40 cases (1987-2012). Journal of The American Veterinary Medical Association , 247(6): 650-658. DOI : http://www.dx.doi.org/10.2460/javma.247.6.650

McArthur S, Wilkinson R, and Meyer J (2004). Medicines and surgery of tortoise and turtles. Blackwell publishing ltd, pp. 31-407. available at : https://vetbooks.ir/medicine-and-surgery-of-tortoises-and-turtles/

Miller I, and Eric R (2015). Fowler's Zoo and Wild Animal Medicine, Cap. 4 Chelonians (Turtles, Tortoises) Saunders, an imprint of Elsevier Inc, available at: https://www.sciencedirect.com/science/article/pii/B9781455773978000049?via\%3Dihub

Mitchell M, and Tully TN (2008). Manual of Exotic Pet Practice. Saunders Elsevier, pp. 243-245. Available at: https://books.google.co.id/books?id=JMTUKwzPEvwC\&pg=PA245\&lpg=PA245\&dq=plastron+osteotomy\&source=bl\&ots=R1 rpkyDoOS\&sig=ACfU3U0GDia3TU uG8yfOumAGcWSx23Uhw\&hl=en\&sa=X\&ved=2ahUKEwihgonP3dPqAhUVH7cAHV U5B08Q6AEwBXoECAkQAQ\#v=onepage $\& \mathrm{q}=$ plastron\%20osteotomy $\& \mathrm{f}=$ false

Rodrigues MC, Lima WC, Quessada AM, Silva FAN, Silva LMC, de Souza AB, de Moura CRC, and Lima DASD (2015). Celiotomy by plastrotomy in a yellow-footed tortoise (Geochelone denticulata). Pesquisa Veterinaria Brasileira, 35 (2): 173-176. DOI: https://doi.org/10.1590/S0100-736X2015000200014

Stephen JD, and Scott JS (2019). Mader's Reptile and Amphibian Medicine and Surgery- E-Book. Elsevier. Available at: https://www.sciencedirect.com/book/9780323482530/maders-reptile-and-amphibian-medicine-and-surgery

Wright K (2008). Clinical Management of Bladder Stones in Tortoises. NAVC Conference. Available at: https://www.cabi.org/isc/FullTextPDF/2009/20093019001.pdf 